\title{
Perancangan Sistem Monitoring dan Kontrol Daya Berbasis Internet Of Things
}

\author{
Amir Shodiq ${ }^{1}$, Syamsyarief Baqaruzi ${ }^{1}$, Ali Muhtar ${ }^{1}$ \\ ${ }^{1}$ Program Studi Teknik Elektro Institut Teknologi Sumatera \\ Email: amir.13117015@student.itera.ac.id, syamsyarief.baqaruzi@el.itera.ac.id, ali.muhtar@el.itera.ac.id
}

\begin{abstract}
Electrical energy is a form of energy that comes from a current source which is usually expressed in Watt hour. The energy used by electrical equipment is the rate at which energy (power) is used for the time the equipment is used. To save the electric power used, consumers must know the electricity consumption every day. To limit usage and estimate electricity usage, therefore consumers must be able to monitor and control the consumption of electric power with a system that is easy and not confusing. One of the current technologies that make monitoring easier is an IoT-based system. PEMoS is a tool designed to monitor and control the consumption of electric power. The device used is equipped with a voltage and current sensor that can read the voltage and current in real time with the NodeMCU communication to send data to the user using the internet network. PEMoS has two parts, namely client and server that communicate wirelessly. The data read by the sensor must first be received by the server before being sent to the cloud server. PEMoS also has an android application which is used to control the client and monitor the electrical power sourced from PLN. After testing the tool, an error value of $1.60 \%$ on the voltage sensor reading is obtained, which is still within tolerance limits. For current sensor testing, an error of.... In the communication between the client and the server, there is a delay in sending data for \pm 6 .
\end{abstract}

Keywords : client, server, power, voltage, current, IoT.

\section{INTISARI}

Energi listrik merupakan suatu bentuk energi yang berasal dari sumber arus yang biasanya dinyatakan dalam Watt hour. Energi yang digunakan oleh peralatan listrik merupakan laju penggunaan energi (daya) selama peralatan tersebut digunakan. Untuk menghemat daya listrik yang terpakai maka konsumen harus mengetahui pemakaian listrik tiap harinya. Untuk memberi batasan pemakaian dan memperkirakan pemakain listrik, maka dari itu konsumen harus dapat memonitoring dan mengontrol pemakaian daya listrik dengan sistem yang memudahkan dan tidak membingungkan. Salah satu teknologi saat ini yang memudahkan untuk memonitoring adalah sistem yang berbasis IoT. PEMoS merupakan alat yang dirancang untuk memonitoring serta mengontrol pemakaian daya listrik. Perangkat yang digunakan dilengkapi dengan sensor tegangan dan arus yang dapat membaca tegangan dan arus secara realtime dengan komukasi NodeMCU untuk mengirimkan data ke user menggunakan jaringan internet. PEMoS memiliki dua bagian yaitu client dan server yang berkomunikasi secara wireless. Data yang dibaca oleh sensor harus terlebih dahulu diterima oleh server sebelum dikirimkan ke cloud server. PEMoS juga memiliki aplikasi android yang digunakan untuk mengontrol client dan memonitoring daya listrik yang bersumber dari PLN. Setelah dilakukan pengujian pada alat, didapatkan nilai galat pada pembacaan sensor tegangan sebesar $1.60 \%$ dimana itu masih dalam batas toleransi. Untuk pengujian sensor arus didapatkan galat sebesar $9.93 \%$. Pada komunikasi antara client dan server terdapat keterlambatan pengiriman data selama $\pm 6 \mathrm{~s}$.

Kata kunci: client, server, daya, tegangan, arus, IoT

\section{PENDAHULUAN}

Power and Energi Monitoring System (PEMoS) ini merupakan alat yang dirancang untuk dapat mengetahui besar tegangan masuk dari PLN yang dignunakan dalam rumah tangga, tidak hanya itu alat ini juga dapat mengetahui arus dan beban yang digunakan pada rumah tangga. Sistem dari alat ini adalah memonitoring arus yang melewati setiap terminal (jalur) yang diinginkan, ketika arus pada rangkaian diketahui dan tegangan input diketahui juga nilai daya nyata akan dapat dihitung langsung pada sistem yang telah dibuat. Alat ini dapat dikontrol menggunakan smartphone dari jarak jauh karena alat

Jurnal ELECTRON, Vol. 2 No.1, Mei 2021: 18-26 
ini sudah dirancang menggukan sistem IoT, untuk mengontrol dan memonitoring harus menggunakan internet karena komunikasi dari sistem ini menngunakan internet dalam mengirim datanya. Ketika arus yang ditentukan pada setiap jalur melebihi kapasitas yang telah ditetapkan maka jalur tersebut akan otomatis terputus atau mati, tetapi ketika jalur tersebut nilai arus dan beban kembali normal maka jalur tersebut akan kembali mengalirkan arus.

Energi listrik merupakan suatu bentuk energi yang berasal dari sumber arus yang biasanya dinyatakan dalam Watt hour. Energi yang digunakan oleh peralatan listrik merupakan laju penggunaan energi (daya) selama peralatan tersebut digunakan. Daya merupakan energi yang diperlukan untuk melakukan usaha/kerja. Daya listrik biasanya dinyatakan dalam Watt. Sedangkan daya sebenarnya yang dikonsumsi oleh beban atau suatu peralatan listrik adalah daya nyata $(\mathrm{P})$ yang dinyatakan dalam watt [1]. Untuk menghemat daya listrik yang terpakai maka konsumen harus mengetahui pemakaian listrik tiap harinya, hal ini untuk memberi batasan pemakain daya listrik agar nantinya dapat memperkirakan pemakain perharinya, maka dari itu konsumen harus dapat memonitoring dan mengontrol pemakaian daya listrik dengan sistem yang memudahkan dan tidak membingungkan.

Sistem monitoring konsumsi daya listrik dirancang untuk memperoleh data yang berkaitan dengan pengukuran parameter listrik antara lain arus, tegangan, dan daya secara real time. Pengukuran parameter daya listrik biasanya dilakukan dengan menggunakan instrumentasi sederhana dan proses pendataan secara manual menggunkan sebuah multimeter, sehingga data yang didapat tidak bisa diperoleh setiap saat dan hasilnya terlalu lama untuk didapatkan. Seiring dengan berkembangnya konsep Internet of Things (IoT), aplikasi Android dapat digunakan untuk menampilkan parameter daya listrik khususnya peralatan elektronika. Seperti penggunaan modem Andromax M2Y yang dimanfaatkan sebagai media untuk sistem kontrol dan monitoring perangkat listrik berbasis jaringan wireless [2]. Sistem serupa juga telah dibuat dengan memanfaatkan aplikasi IoT pihak ketiga.

Internet of Things (IoT) mengacu pada penggunaan teknologi informasi, konektivitas jaringan internet dan sensor yang memungkinkan perangkat yang bukan komputer untuk dapat terhubung satu sama lain melalui jaringan internet. Perangkat ini dapat menghasilkan data, mengirim, menerima, mengumpulkan dan saling tukar menukar data. IoT dapat dimanfaatkan untuk mendukung sistem Monitoring daya listrik [3].

Dari sisi perangkat keras, sistem ini dapat dirancang menggunakan sensor tegangan, sensor arus, LCD, mikrokontroler, modul WiFi, komputer, dan smartphone. Sistem monitoring berbasis IoT juga dapat diterapkan untuk rumah pintar (smart home). Sistem ini diimplementasikan menggunakan protokol komunikasi seperti WSN dan Power Line Communication (PLC). Sistem kontrol perangkat listrik rumah bekerja dengan cara mengirim data dari perangkat yang dikontrol melalui jaringan internet pada smartphone. Seperti mikrokontroler NodeMCU yang digunakan untuk mengontrol kondisi on-off peralatan listrik serta dapat juga mengirim data daya ke database server.

\section{LANDASAN TEORI}

\section{A. Internet of Things (IoT)}

Internet of Things atau sering disebut IoT adalah sebuah gagasan dimana semua benda di dunia nyata dapat berkomunikasi satu dengan yang lain sebagai bagian dari satu kesatuan sistem terpadu menggunakan jaringan internet sebagai penghubung. misalnya CCTV yang terpasang di sepanjang jalan dihubungkan dengan koneksi internet dan disatukan di rung kontrol yang jaraknya mungkin puluhan kilometer. atau sebuah rumah cerdas yang dapat dimanage lewat smartphone dengan bantuan koneksi internet. Pada dasarnya perangkat IoT terdiri dari sensor sebagai media pengumpul data, sambungan internet sebagai media komuniakasi dan server sebagai pengumpul informasi yang diterima sensor dan untuk Analisa [4].

Ide awal Internet of Things pertama kali dimunculkan oleh Kevin Ashton pada tahun 1999 dimana benda-benda di sekitar kita dapat berkomunikasi antara satu sama lain melalui sebuah jaringan seperti internet. Berawal dari Auto-ID Center, teknologi yang berbasis pada Radio Frequency Identification (RFID) yang merupakan identifikasi kode produk elektronik yang bersifat unik ini kemudian berkembang menjadi teknologi bahwa pada setiap benda dapat memiliki alamat Internet Protocol (IP). Dengan semakin berkembangnya infrastruktur internet, maka kita menuju babak berikutnya, di mana bukan hanya smartphone atau komputer saja yang dapat terkoneksi dengan internet. Namun berbagai macam benda nyata akan terkoneksi dengan internet. 
Saat ini milyaran orang saling terhubung melalui jaringan internet, mereka saling bertukar pengetahuan, hiburan, dan lain-lain melintasi kota dan negara bahkan benua. Internet telah menghubungkan orang di seluruh dunia [5].

\section{B. Wireless Sensor Network (WSN)}

Dalam perkembangannya, bukan hanya manusia yang butuh terkoneksi dengan jaringan komputer, namun juga perangkat fisik seperti sensor butuh untuk terhubung dalam jaringan untuk melakukan telemonitoring parameter fisik pada lingkungan sampai dengan proses pengendalian. Wireless Sensor Network (WSN) terdiri dari node individu yang mampu berinteraksi dengan lingkungan mereka dengan merasakan atau mengendalikan parameter fisik. Node ini harus bekerja sama untuk memenuhi tugas-tugas mereka, dan mereka menggunakan komunikasi nirkabel (tanpa kabel) untuk memungkinkan kolaborasi ini. Mikrokontroler berfungsi untuk melakukan fungsi perhitungan, mengontrol dan memproses device-device yang terhubung. Power supply berfungsi sebagai sumber energi bagi sistem wireless sensor secara keseluruhan. Memori eksternal berfungsi sebagai tambahan memori bagi sistem wireless sensor. Sensor berfungsi untuk men-sensing besaran-besaran fisik yang hendak diukur dan mengubah besaran yang diukur menjadi energi listrik yang kemudian diolah oleh Analog to Digital Converter (ADC) menjadi deretan pulsa terkuantisasi yang bisa dibaca dan diproses oleh mikrokontroler [6].

\section{Mikrokontroler}

Mikrokontroler adalah suatu chip berupa IC (Integrated Circuit) yang dapat menerima sinyal input, mengolahnya dan memberikan sinyal output sesuai dengan program yang diisikan ke dalamnya. Sinyal input mikrokontroler berasal dari sensor yang merupakan informasi dari lingkungan sedangkan sinyal output ditujukan kepada aktuator yang dapat memberikan efek ke lingkungan. Jadi secara sederhana mikrokontroler dapat diibaratkan sebagai otak dari suatu perangkat/produk yang mempu berinteraksi dengan lingkungan sekitarnya.

Mikrokontroler pada dasarnya adalah komputer dalam satu chip, yang di dalamnya terdapat mikroprosesor, memori, jalur Input/Output (I/O) dan perangkat pelengkap lainnya. Kecepatan pengolahan data pada mikrokontroler lebih rendah jika dibandingkan dengan
PC. Pada PC kecepatan mikroprosesor yang digunakan saat ini telah mencapai orde $\mathrm{GHz}$, sedangkan kecepatan operasi mikrokontroler pada umumnya berkisar antara 1-16 MHz. Begitu juga kapasitas RAM dan ROM pada PC yang bisa mencapai orde Gbyte, dibandingkan dengan mikrokontroler yang hanya berkisar pada orde byte/Kbyte. Meskipun kecepatan pengolahan data dan kapasitas memori pada mikrokontroler jauh lebih kecil jika dibandingkan dengan komputer personal, namun kemampuan mikrokontroler sudah cukup untuk dapat digunakan pada banyak aplikasi terutama karena ukurannya yang kompak. Mikrokontroler sering digunakan pada sistem yang tidak terlalu kompleks dan tidak memerlukan kemampuan komputasi yang tinggi.

Sistem yang menggunakan mikrokontroler sering disebut sebagai embedded system atau dedicated system. Embeded system adalah sistem pengendali yang tertanam pada suatu produk, sedangkan dedicated system adalah sistem pengendali yang dimaksudkan hanya untuk suatu fungsi tertentu. Sebagai contoh, printer adalah suatu embedded system karena di dalamnya terdapat mikrokontroler sebagai pengendali dan juga dedicated system karena fungsi pengendali tersebut berfungsi hanya untuk menerima data dan mencetaknya. Hal ini berbeda dengan suatu PC yang dapat digunakan untuk berbagai macam keperluan, sehingga mikroprosesor pada PC sering disebut sebagai general purpose microprocessor (mikroprosesor serba guna). Pada PC berbagai macam software yang disimpan pada media penyimpanan dapat dijalankan, tidak seperti mikrokontroler hanya terdapat satu software aplikasi.

Penggunaan mikrokontroler antara lain terdapat pada bidang-bidang berikut ini.

1. Otomotif : Engine Control Unit, Air Bag, fuel control, Antilock Braking System, sistem pengaman alarm, transmisi automatik, hiburan, pengkondisi udara, speedometer dan odometer, navigasi, suspensi aktif.

2. Perlengkapan rumah tangga dan perkantoran : sistem pengaman alarm, remote control, mesin cuci, microwave, pengkondisi udara, timbangan digital, mesin photocopy, printer, mouse.

3. Pengendali peralatan di industri.

4. Robotika

Saat ini mikrokontroler 8bit masih menjadi jenis mikrokontroler yang paling populer dan paling banyak digunakan. Maksud dari mikrokontroler 8bit adalah 
data yang dapat diproses dalam satu waktu adalah 8 bit, jika data yang diproses lebih besar dari 8bit maka akan dibagi menjadi beberapa bagian data yang masing-masing terdiri dari 8 bit. Masing-masing mikrokontroler mempunyai cara dan bahasa pemrograman yang berbeda, sehingga program untuk suatu jenis mikrokontroler tidak dapat dijalankan pada jenis mikrokontroler lain. Untuk memilih jenis mikrokontroler yang cocok dengan aplikasi yang dibuat terdapat tiga kriteria yaitu:

1. Dapat memenuhi kebutuhan secara efektif \& efisien. Hal ini menyangkut kecepatan, kemasan/packaging, konsumsi daya, jumlah RAM dan ROM, jumlah I/O dan timer, harga per unit.

2. Bahasa pemrograman yang tersedia.

3. Kemudahan dalam mendapatkannya.

Mikrokontroler adalah salah satu dari bagian dasar dari suatu sistem komputer. Meskipun mempunyai bentuk yang jauh lebih kecil dari suatu komputer pribadi dan komputer mainframe, mikrokontroler dibangun dari elemen-elemen dasar yang sama. Secara sederhana, komputer akan menghasilkan output spesifik berdasarkan inputan yang diterima dan program yang dikerjakan. Seperti umumnya komputer, mikrokontroler adalah alat yang mengerjakan instruksiinstruksi yang diberikan kepadanya. Artinya, bagian terpenting dan utama dari suatu sistem terkomputerisasi adalah program itu sendiri yang dibuat oleh seorang programmer. Program ini menginstruksikan komputer untuk melakukan jalinan yang panjang dari aksi-aksi sederhana untuk melakukan tugas yang lebih kompleks yang diinginkan oleh programmer.

Mikrokontroler tersusun dalam satu chip dimana prosesor, memori, dan I/O terintegrasi menjadi satu kesatuan kontrol sistem sehingga mikrokontroler dapat dikatakan sebagai komputer mini yang dapat bekerja secara inovatif sesuai dengan kebutuhan sistem. Sistem running bersifat berdiri sendiri tanpa tergantung dengan komputer sedangkan parameter komputer hanya digunakan untuk download perintah instruksi atau program. Langkah-langkah untuk download komputer dengan mikrokontroler sangat mudah digunakan karena tidak menggunakan banyak perintah. Pada mikrokontroler tersedia fasilitas tambahan untuk pengembangan memori dan I/O yang disesuaikan dengan kebutuhan sistem. Harga untuk memperoleh alat ini lebih murah dan mudah didapat.

\section{NodeMCU ESP 8266}

ESP 8266 adalah sebuah chip yang sudah lengkap dimana didalamnya sudah termasuk processor, memori dan juga akses ke GPIO. Hal ini menyebabkan ESP8266 dapat secara langsung menggantikan Arduino dan ditambah lagi dengan kemampuannya untuk mensupport koneksi wifi secara langsung. IoT (Internet of Things) semakin berkembang seiring dengan perkembangan mikrokontroler, module yang berbasiskan Ethernet maupun wifi semakin banyak dan beragam dimulai dari Wiznet, Ethernet shield hingga yang terbaru adalah Wifi module yang dikenal dengan ESP8266. Ada beberapa jenis ESP8266 yang dapat ditemui dipasaran, namun yang paling mudah didapatkan di Indonesia adalah type ESP-01, 07, dan 12 dengan fungsi yang sama perbedaannya terletak pada GPIO pin yang disediakan [7].

Tegangan kerja ESP-8266 adalah sebesar 3.3V, sehingga untuk penggunaan mikrokontroler tambahannya dapat menggunakan board arduino yang memiliki fasilitas tengangan sumber $3.3 \mathrm{~V}$, akan tetapi akan lebih baik jika membuat secara terpisah level shifter untuk komunikasi dan sumber tegangan untuk wifi module ini. Karena wifi module ini dilengkapi dengan Mikrokontroler dan GPIO sehingga banyak orang yang mengembangkan firmware untuk dapat mengunakan module ini tanpa perangkat mikrokontroler tambahan. Firmware yang digunakan agar wifi module ini dapat bekerja standalone.

Istilah NodeMCU sebenarnya mengacu pada firmware yang digunakan daripada perangkat keras development kit. NodeMCU bisa dianalogikan sebagai board Arduino-nya ESP8266. NodeMCU telah menggabungkan ESP8266 ke dalam sebuah board yang kompak dengan berbagai fungsi layaknya mikrokontroler ditambah juga dengan kemampuan akses terhadap Wifi juga chip komunikasi USB to Serial sehingga untuk memprogramnya hanya diperlukan ekstensi kabel data mikro USB. Secara umum ada tiga produsen NodeMCU yang produknya kini beredar di pasaran: Amica, DOIT, dan Lolin/WeMos. Dengan beberapa varian board yang diproduksi yakni V1, V2 dan V3. Generasi kedua atau V2 adalah pengembangan dari versi sebelumnya (V1), dengan chip yang ditingkatkan dari sebelumnya ESP12 menjadi ESP-12E dan IC USB to Serial diubah dari CHG340 menjadi CP2102 [8].
E. $M y S Q L$ 
MySQL adalah Sebuah program database server yang mampu menerima dan mengirimkan datanya sangat cepat, multi user serta menggunakan peintah dasar SQL (Structured Query Language). MySQL merupakan dua bentuk lisensi, yaitu Free Software dan Shareware. MySQL Merupakan sebuah database server yang free, artinya kita bebas menggunakan database ini untuk keperluan pribadi atau usaha tanpa harus membeli atau membayar lisensinya. MySQL pertama kali dirintis oleh seorang programmer database bernama Michael Widenius. Selain database server, MySQL juga merupakan program yang dapat mengakses suatu database MySQL yang berposisi sebagai server, yang berarti program kita berposisi sebagai client. Jadi MySQL adalah sebuah database yang dapat digunakan sebagai client mupun server. Database MySQL merupakan suatu perangkat lunak database yang berbentuk database relasional atau disebut Relational Database Management System (RDBMS) yang menggunakan suatu bahasa permintaan yang bernama SQL (Structured Query Language) [8]

\section{METODE PENELITIAN}

\section{A. Perancangan Sistem Hardware}

Perangkat utama yang digunakan terdiri atas subsistem akuisisi data, subsistem kendali (kontrol), dan subsistem antarmuka (interface). Ketiga subsistem tersebut terpisah masing-masing berdasarkan letaknya. Subsistem akuisisi data digunakan untuk pembacaan sensor yang digunakan. Pada subsistem kontrol digunakan untuk mengontrol dan melakukan pembacaan data. Sedangkan pada subsistem antarmuka digunakan untuk menampilkan data yang telah dibaca melalui subsistem kontrol. Dalam subsistem kontrol pengguna akan menerima informasi dari arus dan tegangan pembacaan serta daya yang terbaca secara real-time.

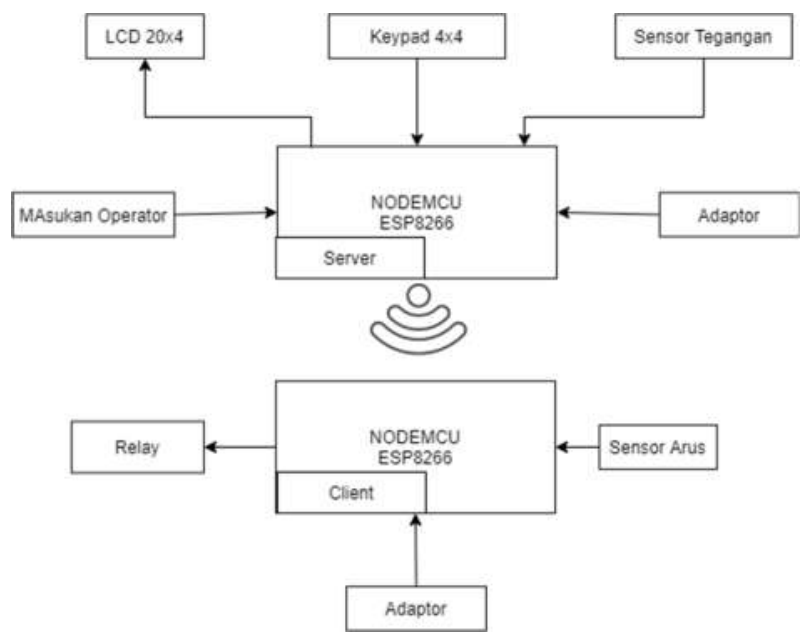

Gambar 3. 1 Blog diagram sistem PEMoS

Pada blog diagram diatas dapat dilihat terdapat dua komponen penting yaitu server dan client, dimana data yang terbaca oleh client akan dikirimkan ke server terlebih dahulu kemudian akan diteruskan atau dikirimkan ke cloud server. Pada client terdapat sensor arus dan relay yang berfungsi sebagai saklar elektrik untuk menghidupkan ataupun mematikan sumber tegangan pada client tersebut.

Komponen pada subsistem ini adalah ESP8266 yang berfungsi sebagai komunikasi hardware dengan jaringan internet atau database. Pada perancangan ini sistem akan dapat mengirim hasil sensing mikrokontroler menuju database dan dapat mengunduh data yang terdapat pada database.

\section{B. Perancangan Sistem Software}

Pada tahap perancangan, penulis menentukan sistem alat dan aplikasi. Kemudian menentukan komponen yang dibutuhkan serta skema pemasangan tiap komponen. Perancangan alat ini dapat dilakukan dengan melakukan pengujian pengiriman data ke database terlebih dahulu, untuk implementasi pertama kita menggukan sebuah localhost untuk mengirimkan datanya dan menyimpan menggunakan database MySQL. Kemudaian setelah data yang diinginkan dapat dikirimkan ke database maka data tersebut dapat dikonversi ke daya dan energi. Data yang telah dsimpan di database dapat diambil dan ditampilkan pada aplikasi android. 


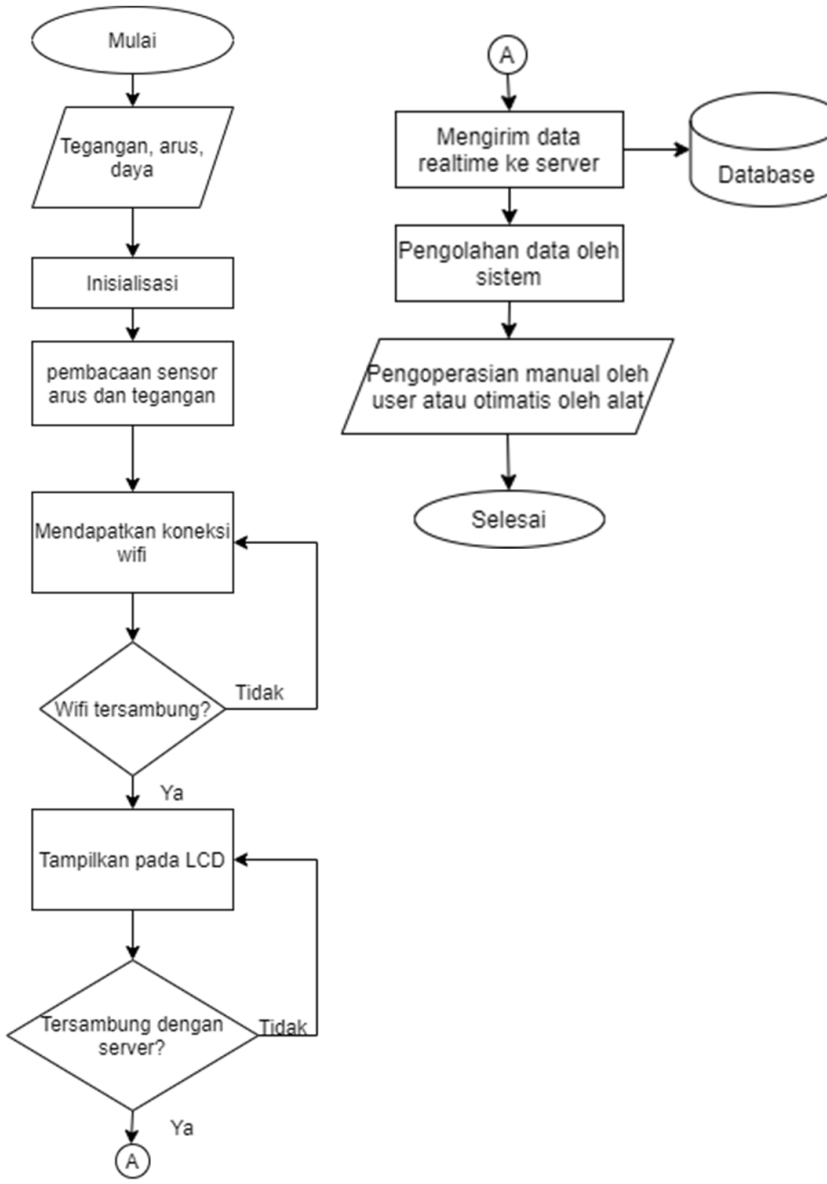

Informasi yang disampaikan dalam antarmuka tersebut berupa kontrol, monitoring yang berisi informasi tegangan, arus, dan daya, pada biaya kita dapat melihat biaya dari pemakaian listrik, dan pada riwayat kita dapat mengetahui Riwayat pemakaian listrik sebelumnya.

Pada aplikasi dapat menampilkan beban daya, biaya listrik, dan pengontrol yang menjadi fitur utama dari alat kami, selain itu aplikasi ini juga memiliki fitur login yang berguna untuk pemakain alat ini secara bersamaan, agar alat ini tidak dikendalikan banyak orang pada setiap alatnya.

\section{Perancangan Pengujian}

Pada sistem PEMoS pengujian yang dilakukan yaitu pembacaan tegangan dan arus pada listrik yang bersumber dari PLN. Sistem PEMoS memiliki dua bagian yaitu clinet dan server, dimana kedua bagian ini saling berkomunikasi mengirimkan data secara wireless, tetapi untuk server berkomunikasi juga dengan cloud server agar data yang terbaca dapat lihat kembali dilain waktu.

\section{HASIL PENELITIAN DAN PEMBAHASAN}

\section{A. Akurasi Sensor}

1. Hasil Pengujian Sensor Tegangan ZMPT101B

Pengujian ini dilakukan kalibrasi terlebih dahulu untuk melakukan proses pengecekan alat ukur agar mendapatkan akurasi dengan membandingkan standar alat ukur. Pada pengujian tegangan ini dilakukan kalibrasi dengan membandingkan hasil dari pengujian terhadap hasil pengukuran dengan menggunakan multimeter. Kalibrasi yang dilakukan pada sensor tegangan ini diperoleh dari percobaan yang nantinya hasilnya dibandingkan dengan pembacaan pada multimeter. Data pengujian sensor tegangan diperoleh dari penggunaan sensor ZMPT101B VS01 dengan menggunaan regulator tegangan yang divariasikan dari nilai $0-240$ Volt Dari pengujian tersebut diperoleh hasil terbaik yang ditunjukkan pada Tabel 4.1.

Tabel 4. 1 Hasil pengujian sensor tegangan

\begin{tabular}{|c|c|c|c|c|}
\hline $\begin{array}{c}\text { Pengujian } \\
\text { Ke- }\end{array}$ & $\begin{array}{c}\text { Pembacaan } \\
\text { Multimeter }\end{array}$ & $\begin{array}{c}\text { Pembacaan } \\
\text { Sensor }\end{array}$ & Selisih & $\begin{array}{c}\text { Galat } \\
(\%)\end{array}$ \\
\hline 1 & 222 & 224.5 & 2.5 & 1.13 \\
\hline 2 & 222 & 226.7 & 4.7 & 2.12 \\
\hline 3 & 221 & 226.6 & 5.6 & 2.52 \\
\hline 4 & 222 & 225.0 & 3.0 & 1.35 \\
\hline 5 & 223 & 225.0 & 2.0 & 0.90 \\
\hline Rata-rata & 222 & 225.56 & 3.56 & 1.6 \\
\hline
\end{tabular}

$$
\begin{gathered}
=\left|\frac{\text { Gasil }}{\text { Hasil Pengukuran }- \text { Hasil Sensor }}\right| \times 100 \% \\
\quad \text { Rata }- \text { rata }=\sum \frac{x 1+x 2+x 3+\cdots+x n}{n}
\end{gathered}
$$




\section{Pengujian Sensor Tegangan ZMPT101B}

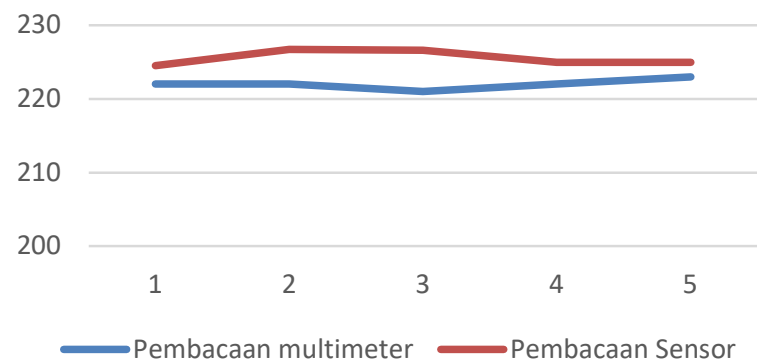

Gambar 4. 1 Grafik perbandingan pembacaan sensor dengan pembacaan pada multimeter

Dari hasil pengujian sensor tegangan menunjukkan bahwa galat yang didapatkan sebesar $1.60 \%$, yang artinya masih dalam batas toleransi karena dalam pengukuran sensor tegangan tidak selamanya akurat mengingat dari prinsip kerja dari karakteristik sensor itu sendiri.

\section{Pengujian Sensor Arus ACS712}

Pengujian sensor arus ACS712 Data pengujian arus diperoleh dengan memvariasikan beban listrik sehingga diperoleh arus pada rentang $0-2$ A. Rincian pengujian sensor arus ACS712 dilakukan dengan pengukuran arus dengan multimeter digital. Hasil perincian data pengukuran sensor ACS712 terdapat pada gambar 4.2

Tabel 4. 2 Hasil pengujian sensor tarus ACS712

\begin{tabular}{|c|c|c|c|c|}
\hline $\begin{array}{c}\text { Alat yang } \\
\text { diuji }\end{array}$ & $\begin{array}{c}\text { Pembacaan } \\
\text { Multimeter }\end{array}$ & $\begin{array}{c}\text { Pembacaan } \\
\text { Sensor }\end{array}$ & Selisih & $\begin{array}{c}\text { Galat } \\
(\%)\end{array}$ \\
\hline Setrika & 1.570 & 1.480 & 0.090 & 5.730 \\
\hline Kipas & 0.220 & 0.200 & 0.020 & 9.090 \\
\hline Charger & 0.290 & 0.260 & 0.030 & 10.240 \\
\hline $\begin{array}{c}\text { Rice } \\
\text { cooker }\end{array}$ & 1.360 & 1.500 & 0.140 & 10.290 \\
\hline $\begin{array}{c}\text { Lampu } \\
\text { 3W }\end{array}$ & 0.014 & 0.016 & 0.002 & 14.290 \\
\hline \multicolumn{5}{|c|}{ Rata-rata } \\
\hline
\end{tabular}

$$
\begin{aligned}
& \text { Galat } \\
& =\left|\frac{\text { Hasil Pengukuran }- \text { Hasil Sensor }}{\text { Hasil Pengukuran }}\right| \times 100 \%
\end{aligned}
$$

$$
\text { Rata }- \text { rata }=\sum \frac{x 1+x 2+x 3+\cdots+x n}{n}
$$

Dari hasil pengujian sensor water flow menunjukkan bahwa galat yang didapatkan sebesar 4,40 \%, yang artinya masih dalam batas toleransi karena dalam pengukuran sensor water flow tidak selamanya akurat mengingat dari prinsip kerja dari karakteristik sensor itu sendiri.

\section{Pengujian Aktuator}

Pada pengujian aktuator ini yaitu menghitung delay waktu merespon kontrol dari aplikasi, kontrol dari aplikasi akan diterima terlebih dahulu oleh server kemudian akan dikirimkan pada client. Aktuator yang digunakan adalah. Aktuator yang digunakan adalah relay yang digunakan sebagai saklar elektrik pada setiap client.

Tabel 4. 3 Pengujian aktuator terhadap waktu delay

\begin{tabular}{|c|c|c|c|}
\hline $\begin{array}{c}\text { Pengjian } \\
\text { Ke- }\end{array}$ & $\begin{array}{c}\text { Client } \\
\text { ke- }\end{array}$ & $\begin{array}{c}\text { Delay pada } \\
\text { server }\end{array}$ & $\begin{array}{c}\text { Delay pada } \\
\text { client }\end{array}$ \\
\hline \multirow{4}{*}{1} & 1 & $1.00 \mathrm{~s}$ & $6.20 \mathrm{~s}$ \\
\cline { 2 - 4 } & 2 & $1.00 \mathrm{~s}$ & $11.35 \mathrm{~s}$ \\
\cline { 2 - 4 } & 3 & $1.00 \mathrm{~s}$ & $15.68 \mathrm{~s}$ \\
\cline { 2 - 4 } & 4 & $1.00 \mathrm{~s}$ & $21.20 \mathrm{~s}$ \\
\hline \multirow{4}{*}{2} & 1 & $1.00 \mathrm{~s}$ & $6.40 \mathrm{~s}$ \\
\cline { 2 - 4 } & 2 & $1.00 \mathrm{~s}$ & $12.20 \mathrm{~s}$ \\
\cline { 2 - 4 } & 3 & $1.00 \mathrm{~s}$ & $16.30 \mathrm{~s}$ \\
\cline { 2 - 4 } & 4 & $1.00 \mathrm{~s}$ & $22.10 \mathrm{~s}$ \\
\hline \multirow{4}{*}{3} & 1 & $1.00 \mathrm{~s}$ & $6.20 \mathrm{~s}$ \\
\cline { 2 - 4 } & 2 & $1.00 \mathrm{~s}$ & $11.80 \mathrm{~s}$ \\
\cline { 2 - 4 } & 3 & $1.00 \mathrm{~s}$ & $16.10 \mathrm{~s}$ \\
\hline \multirow{4}{*}{4} & 4 & $1.00 \mathrm{~s}$ & $21.90 \mathrm{~s}$ \\
\cline { 2 - 4 } & 2 & $1.00 \mathrm{~s}$ & $6.60 \mathrm{~s}$ \\
\cline { 2 - 4 } & 3 & $1.00 \mathrm{~s}$ & $12.40 \mathrm{~s}$ \\
\cline { 2 - 4 } & 4 & $1.00 \mathrm{~s}$ & $16.80 \mathrm{~s}$ \\
\hline \multirow{4}{*}{5} & 1 & $1.00 \mathrm{~s}$ & $22.00 \mathrm{~s}$ \\
\cline { 2 - 4 } & 2 & $1.00 \mathrm{~s}$ & $6.40 \mathrm{~s}$ \\
\cline { 2 - 4 } & 3 & $1.00 \mathrm{~s}$ & $12.30 \mathrm{~s}$ \\
\cline { 2 - 4 } & 4 & $1.00 \mathrm{~s}$ & $16.20 \mathrm{~s}$ \\
\hline
\end{tabular}

Hasil dari pengujian ini didapatkan nilai delay pada server memiliki nilai yang sangat kecil, tetapi nilai delay pada client memiliki nilai lebih besar, hal ini terjadi karena komunikasi antara server dan client yang membutuhkan waktu sekitar $6 \mathrm{~s}$ setiap pengiriman data dan pada saat pengiriman data tidak dapat terjadi secara 
bersamaan. Semakin banyak client yang digunakan maka nilai delay juga akan semakin besar.

\section{B. Komunikasi Data}

1. Penerimaan data tegangan dan arus

Data tegangan dan arus yang diterima database dari pembacaan tegangan listrik PLN. Data selengkapnya penerimaan pembacaan sensor tegangan dan arus ditunjukan pada Gambar 4.6.

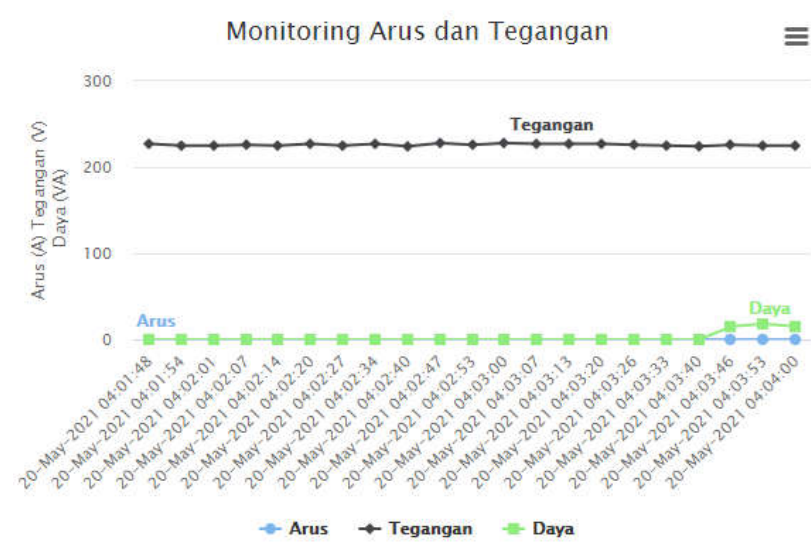

Gambar 4. 2 Grafik data tegangan dan arus

2. Penerimaan data kontrol

Data arus yang diterima thingspeak merupakan data arus yang diperoleh dari penguran arus pembangkitan dari turbin angin. Data arus pembangkitan ditunjukan pada gambar 4.7.

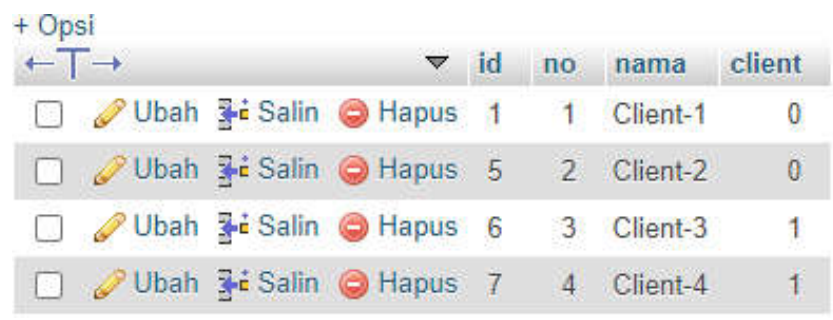

Gambar 4.7 Data kontrol yang terkirim ke database

\section{KESIMPULAN}

1. Sistem Monitoring dan kontrol tegangan, arus dan daya listrik pada rumah berbasis IoT dapat dirancang dan digunakan.
2. Pembacaan akuisisi data sensor pada sistem PEMoS telah berhasil disimpan pada database.

3. Pembacaan daya yang telah dilakukan mendekati hasil yang akurat.

\section{REFERENSI}

[1] S. Suryaningsih, S. Hidayat, and F. Abid, "Rancang Bangun Alat Pemantau Penggunaan Energi Listrik Rumah Tangga Berbasis Internet," no. June 2017, pp. SNF2016-ERE87-SNF2016-ERE-90, 2016, doi: $10.21009 / 0305020617$.

[2] T. D. Hendrawati, Y. D. Wicaksono, and E. Andika, "Internet of Things: Sistem KontrolMonitoring Daya Perangkat Elektronika," JTERA (Jurnal Teknol. Rekayasa), vol. 3, no. 2, p. $177, \quad 2018, \quad$ doi: 10.31544/jtera.v3.i2.2018.177-184.

[3] B. Prayitno, "Prototipe Sistem Monitoring Penggunaan Daya Listrik Peralatan Elektronik Rumah Tangga Berbasis Internet of Things," Petir, vol. 12, no. 1, pp. 72-80, 2019, doi: 10.33322/petir.v12i1.333.

[4] Y. Efendi, "Internet Of Things (Iot) Sistem Pengendalian Lampu Menggunakan Raspberry Pi Berbasis Mobile," J. Ilm. Ilmu Komput., vol. 4, no. 2, pp. 21-27, 2018, doi: 10.35329/jiik.v4i2.41.

[5] Tashia, "Dari Internet Of Thing Menuju Smart City dan Smart People," 2015. https://aptika.kominfo.go.id/2015/12/dariinternet-of-thing-menuju-smart-city-dan-smartpeople/ (accessed May 20, 2021).

[6] I. G. P. M. Eka Putra, I. A. D. Giriantari, and L. Jasa, "Monitoring Penggunaan Daya listrik Sebagai Implementasi Internet of Things Berbasis Wireless Sensor Network," Maj. Ilm. Teknol. Elektro, vol. 16, no. 3, p. 50, 2017, doi: 10.24843/mite.2017.v16i03p09.

[7] H. Shull, "SISTEM PENGAMANAN PINTU RUMAH BERBASIS Internet Of Things (IoT) Dengan ESP8266," Science (80-. )., vol. 195, no. 4279, p. 639, 1977, [Online]. Available: https://ojs.uniska-

bjm.ac.id/index.php/JIT/article/view/661. 
Jurnal ELECTRON, Vol. 2, No.1, Mei 2021, Hal. 18-26

e-ISSN 2622-6588

[8] L. S. Pamungkas and N. Damastuti, "1,2 1, 2," vol. IV, pp. 46-53, 2018. 